\title{
Evidence for Physiological Importance of Calcitonin in the Regulation of Plasma Calcium in Rats
}

\author{
D. N. Kalu, A. HadjI-Georgopoulos, and G. V. Foster \\ From the Department of Physiology, The Johns Hopkins University School of \\ Medicine, Baltimore, Maryland 21205
}

\begin{abstract}
A в S T RACT To determine the physiological importance of calcitonin in the regulation of plasma calcium, studies were carried out in fasting animals to $(a)$ assess the acute effects of thyroparathyroidectomy (TPTX) and thyroidectomy (TX) on plasma and urinary calcium; $(b)$ investigate whether the changes in plasma calcium produced by removal of the glands were dependent on the presence of the kidney; and $(c)$ determine if the effect of TPTX on plasma calcium is affected by age. Except where otherwise indicated, all studies were carried out on fasting male Wistar rats weighing over $300 \mathrm{~g}$. The following observations were made. (a) TPTX and TX caused an increase in plasma calcium in nephrectomized animals. (b) This increase was not dependent on nephrectomy since in intact animals bearing autoparathyroid transplants TX also caused a significant rise in the mean plasma calcium level $\left(0.37 \mathrm{mg} / 100 \mathrm{ml}\right.$ at $\left.1 \frac{1}{2} \mathrm{~h}\right)$. (c) Urinary calcium increased twofold in the 3 -h period immediately after TX. $(d)$ In unnephrectomized immature $(50-\mathrm{g})$ rats, TPTX caused a progressive decrease in plasma calcium in contrast to old $(360-\mathrm{g})$ rats, where a significant fall observed at $6 \mathrm{~h}$ was preceded by an increase in plasma calcium $\left(0.5 \mathrm{mg} / 100 \mathrm{ml}\right.$ at $\left.1 \frac{1}{2} \mathrm{~h}\right)$. From these observations we conclude that: $(a)$ calcitonin must play an important physiological role in the regulation of plasma calcium since the termination of its basal secretion caused an immediate but transient increase in plasma calcium in old unfed rats; $(b)$ the relative importance of calcitonin and parathyroid hormone in the acute regulation of plasma calcium is agerelated; and $(c)$ the action of parathyroid hormone on bone may be modified by changes in ambient calcitonin concentration.
\end{abstract}

Received for publication 17 July 1974 and in revised form 19 December 1974.

\section{INTRODUCTION}

It has been proposed that calcitonin plays an important physiological role in protecting against postprandial hypercalcemia. According to this hypothesis, feeding stimulates the secretion of calcitonin, either as a direct consequence of hypercalcemia or indirectly by enhancing the secretion of gastrointestinal hormones that in turn stimulate calcitonin secretion (1). The resulting inhibition of calcium transport from bone (2) prevents an excessive increase in plasma calcium. This view is supported by several observations. First, calcium infused in athyroid patients maintained on replacement thyroxine causes a more prolonged hypercalcemia than in normal subjects (3). Second, calcium administered by gavage raises plasma calcium more in thyroparathyroidectomized than in normal animals (1). Third, in rats bearing autoparathyroid transplants, thyroidectomy causes an immediate increase in plasma calcium during the "dark" fed period but not in the "light" unfed period (4).

It has not, so far, been possible to define a physiological role for calcitonin in the regulation of plasma calcium level that is unrelated to a calcium load, because except in pigs (5) thyroidectomy has not been found to increase plasma calcium in fasting animals (6).

Recently, we observed that in fasting rats weighing $314 \mathrm{~g}$ plasma calcium remained unchanged $3 \mathrm{~h}$ after thyroparathyroidectomy, in spite of a fivefold increase in urinary calcium (7). Parathyroid ablation increases urinary calcium excretion, as well as diminishing calcium transport from bone. Conversely, the removal of calcitonin secretion should result in increased calcium transport from bone. We therefore postulated that in rats of this age, the effect of the removal of the source of calcitonin on calcium transport from bone is far greater than that of parathyroid ablation, since the fivefold increase in urinary calcium after thyroparathyroidectomy did not lower plasma calcium. 
The purpose of this study is to test this hypothesis and evaluate its consequences. Specific experiments were carried out to: $(a)$ evaluate the acute effects of thyroparathyroidectomy on plasma and urinary calcium; (b) ascertain whether any changes are due specifically to thyroid ablation; $(c)$ assess the influence of age on the effect of thyroparathyroidectomy; and $(d)$ determine the relative importance of calcitonin and parathyroid hormone in the acute regulation of plasma calcium.

\section{METHODS}

Male Wistar rats, maintained on normal Charles River rat diet (Charles River Breeding Laboratories, Wilmington, Mass.), were used in all experiments. They were starved for $24 \mathrm{~h}$ before each experiment.

In all experiments, surgery and bleeding of the animals were done under light ether anesthesia. When urine samples were collected for $3 \mathrm{~h}$, all animals were orally hydrated with water to the extent of about $3 \%$ of their body weight before and $1 \frac{1}{2} \mathrm{~h}$ after surgery.

Throughout the paper, we have used the term "old rats" to indicate animals weighing over $300 \mathrm{~g}$. Calcium and phosphorus were measured in plasma samples, and calcium, creatinine and hydroxyproline were measured in urine samples.

Analytical procedures. Blood samples were collected in ice-cooled heparinized tubes, and plasma was separated within $30 \mathrm{~min}$ in a refrigerated centrifuge. Both plasma and acidified urine samples were frozen at $-20^{\circ} \mathrm{C}$ until analyzed. Calcium was measured by atomic absorption spectrophotometry, phosphorus was measured by the method of Taussky and Shorr (8), creatinine was assessed by the method of Bonsnes and Taussky (9), and hydroxyproline was assayed by the method of Kivirikko, Laitinen, and Prockop (10).

\section{RESULTS}

Experiment 1. Effects of thyroparathyroidectomy on plasma and urinary calcium and phosphorus and urinary hydroxyproline. Rats with a mean weight of $318 \mathrm{~g}$ were sham-operated or thyroparathyroidectomized. Urine samples were collected for $3 \mathrm{~h}$ immediately after surgery, and the animals were then bled from the abdominal aorta.

$3 \mathrm{~h}$ after thyroparathyroidectomy, urinary calcium increased fivefold, while phosphorus excretion decreased, resulting in hyperphosphatemia. Plasma calcium and urinary hydroxyproline and creatinine were unchanged (Fig. 1).

Experiment 2. Effects of thyroparathyroidectomy on plasma calcium and phosphorus in nephrectomized rats. Rats with a mean weight of $318 \mathrm{~g}$ were nephrectomized and then immediately thyroparathyroidectomized or sham-operated. They were bled from the abdominal aorta $3 \mathrm{~h}$ after surgery. There was a greater increase in plasma calcium and phosphorus $3 \mathrm{~h}$ after thyroparathyroidectomy than after nephrectomy alone (Fig. 2).

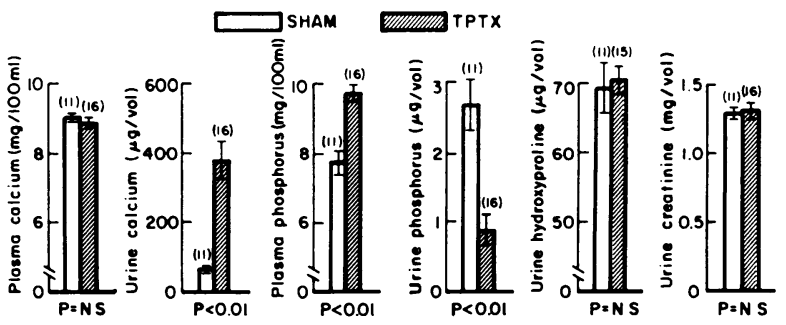

FigUre 1 Effects of thyroparathyroidectomy (TPTX) on 318-g rats. Animals were sham-operated (SHAM) upon or thyroparathyroidectomized. Urine was collected for $3 \mathrm{~h}$ immediately after surgery and the rats then bled from the abdominal aorta. The columns indicate means and the vertical bars SE, with the number of animals in parentheses.

Experiment 3. Effects of thyroidectomy on plasma calcium and phosphorus in nephrectomized rats bearing autoparathyroid transplants. The parathyroid glands of $300-\mathrm{g}$ rats were dissected out and immediately transplanted into the thigh. 3 days later, the animals were bled by orbital sinus puncture, and plasma calcium was determined. The parathyroid glands were considered to have been successfully removed only in rats with plasma calcium levels of less than $6.0 \mathrm{mg} / 100 \mathrm{ml}$. 3-4 wk later, their plasma calcium was reassessed. The transplanted parathyroids were judged to be functional in those rats whose plasma calcium had risen to the pretransplant level.

3 days after the last assessment of calcium, 14 of the animals with functional parathyroids and a mean weight of $337 \mathrm{~g}$ were nephrectomized. Half the rats were im-

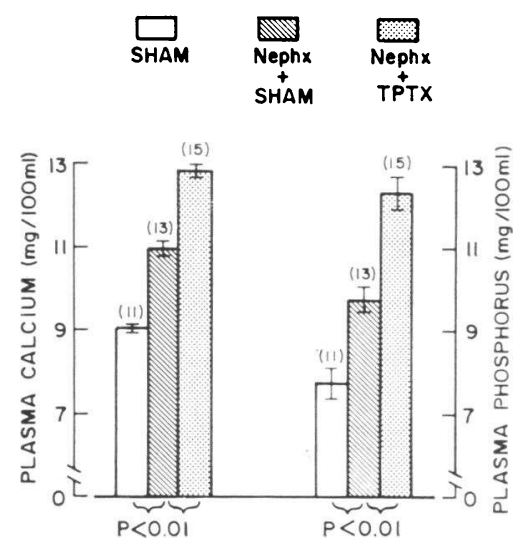

FIgURE 2 Effects of thyroparathyroidectomy (TPTX) on plasma calcium and phosphorus in nephrectomized (NEPHX) 318-g rats. 28 animals were nephrectomized. 15 were immediately thyroparathyroidectomized. The thyroparathyroids of the rest were exposed but not removed and all rats bled from the abdominal aorta after $3 \mathrm{~h}$. The columns indicate means and the vertical bars SE, with the number of animals in parentheses. The unshaded columns are values for sham-operated (SHAM) unnephrectomized animals from Fig. 1.

Calcitonin and Calcium Homeostasis 

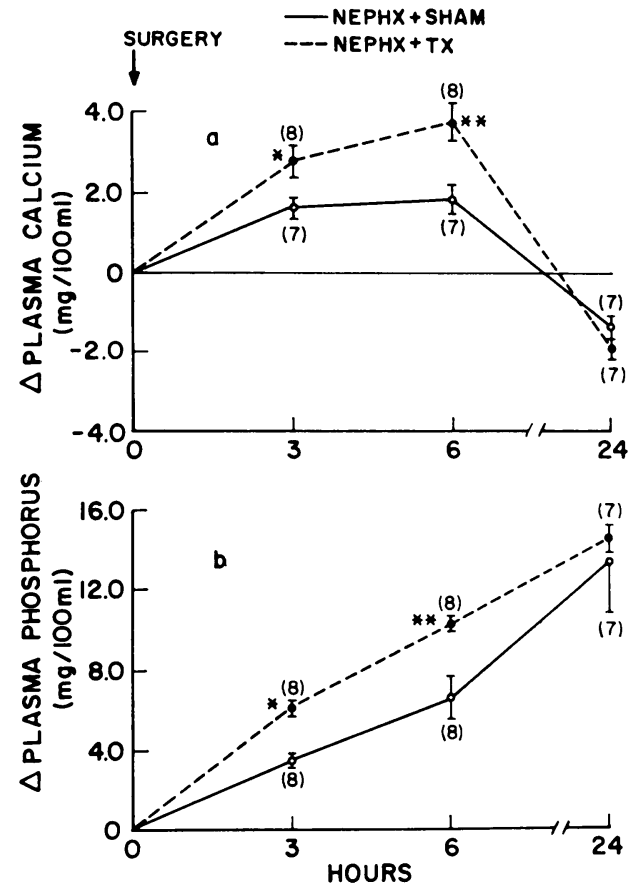

Figure 3 Effects of thyroidectomy (TX) on (a) plasma calcium and (b) plasma phosphorus in nephrectomized (NEPHX) 337-g rats bearing autoparathyroid transplants. Animals bearing functional parathyroid glands were nephrectomized and either thyroidectomized or sham-operated (SHAM). They were bled by orbital sinus puncture just before surgery and 3, 6, and $24 \mathrm{~h}$ later. Each point is the mean difference between preoperative and subsequent values. The vertical bars indicate $\mathrm{SE}$ with the number of animals in parentheses. $* P<0.02$; $* * P<0.01$.

mediately thyroidectomized, and the remainder were sham operated. All animals were bled by orbital sinus puncture immediately before surgery and 3,6 , and $24 \mathrm{~h}$ later.

As in the previous experiment, plasma calcium increased after thyroidectomy. This rise, greater than that due to nephrectomy, was significant at $3 \mathrm{~h}$ and maximal at $6 \mathrm{~h} .24 \mathrm{~h}$ after thyroidectomy, plasma calcium had fallen below the presurgery level (Fig. $3 a$ ). Compared to nephrectomized controls, thyroidectomized rats had a greater increase in plasma phosphorus by 3 and $6 \mathrm{~h}$, but not after $24 \mathrm{~h}$ (Fig. $3 b$ ).

Experiment 4. Relation between the rise in plasma calcium after thyroidectomy and the initial plasma calcium level in nephrectomized rats bearing autoparathyroid transplants. 20 days after the parathyroid glands were transplanted, 34 rats with a mean weight of $344 \mathrm{~g}$ were nephrectomized and immediately thyroidectomized or sham-operated. All animals were bled before and $6 \mathrm{~h}$ after surgery and separated into groups according to their initial plasma calcium level, which varied from $5.16 \pm 0.17 \mathrm{mg} / 100 \mathrm{ml}$ to $9.33 \pm 0.14 \mathrm{mg} / 100$ $\mathrm{ml}$. The increase in plasma calcium $6 \mathrm{~h}$ after thyroidectomy was directly proportional to the presurgery plasma calcium level (Fig. 4).

Experiment 5. Effects of thyroidectomy on plasma and urinary calcium and phosphorus and urinary hydroxyproline in 380-g rats bearing autoparathyroid transplants. Transplantation of the parathyroids and assessment of the success of the operation were carried out as described in exp. 3. Animals bearing functional parathyroids were thyroidectomized or sham-operated, and urine was collected for $3 \mathrm{~h}$ immediately after surgery. All rats were bled before surgery and $1 \frac{1}{2}, 3,6$, and $24 \mathrm{~h}$ later.

Thyroidectomy increased the mean plasma calcium level by $0.37 \mathrm{mg} / 100 \mathrm{ml}$ at $1 \frac{1}{2} \mathrm{~h}$. Subsequently, plasma calcium decreased and by $6 \mathrm{~h}$ had returned to the preoperative value (Fig. $5 a$ and $b$ ). Unlike plasma calcium, plasma phosphorus increased more persistently after thyroidectomy, although the increase was no longer significant at $24 \mathrm{~h}$ (Fig. 5c). In the 3-h period immediately after thyroidectomy, urine calcium increased almost twofold, urine phosphorus decreased slightly but not significantly, and urine creatinine and hydroxyproline were unchanged (Fig. 6). The increase in urinary calcium could not be ascribed to changes in bone matrix resorption (as indicated by urinary hydroxyproline) or changes in glomerular filtration (as indicated by creatinine).

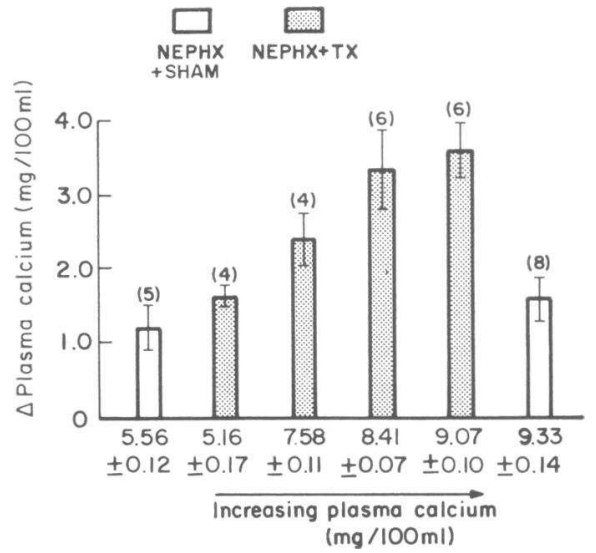

Figure 4 Relation between the rise in plasma calcium after thyroidectomy (TX) and the initial plasma calcium level in nephrectomized (NEPHX) 344-g rats bearing autoparathyroid transplants. Rats in which the parathyroids had been transplanted 20 days previously were nephrectomized and immediately thyroidectomized or sham-operated (SHAM). All animals were bled immediately before and $6 \mathrm{~h}$ after surgery and separated into groups according to their preoperative plasma calcium level, the means $\pm \mathrm{SE}$ of which are shown at the bottom of each column. $\Delta$ Plasma calcium is the mean difference between values before and $6 \mathrm{~h}$ after surgery. The columns indicate means and the vertical bars SE, with the number of animals in parentheses. 

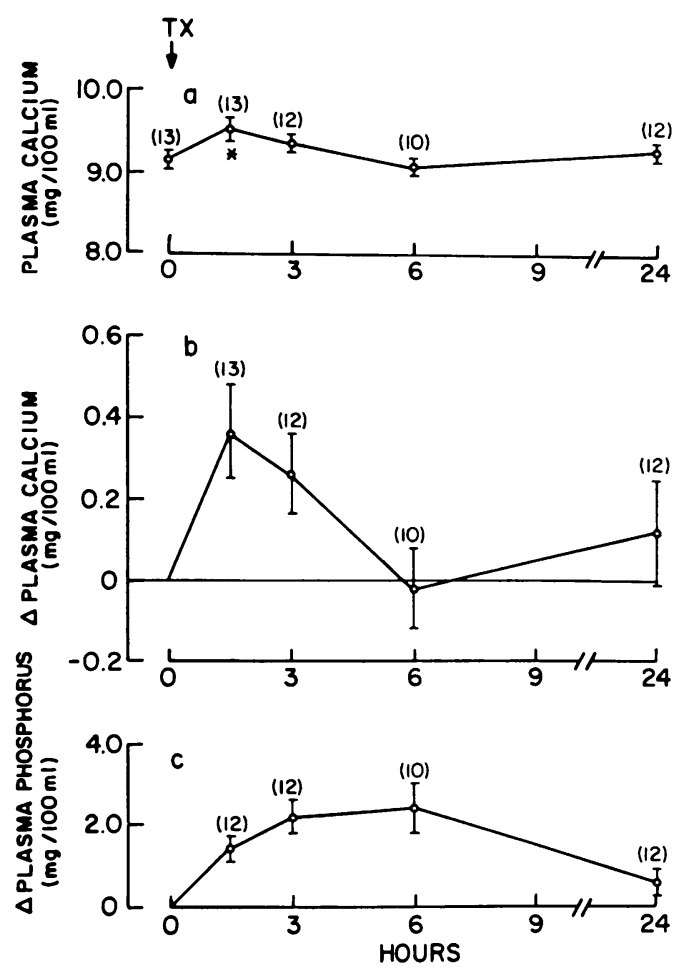

FIGURE 5 Effects of thyroidectomy (TX) on plasma calcium and phosphorus in 380-g rats bearing autoparathyroid transplants. Animals with functional transplants were thyroidectomized and urine collected for $3 \mathrm{~h}$ immediately after surgery. All rats were bled before and $1 \frac{1}{2}, 3,6$, and $24 \mathrm{~h}$ after operation. (a) Each point is the mean plasma calcium. $(b)$ and $(c)$ Each point is the mean difference between the prethyroidectomy and subsequent plasma calcium and phosphorus values, respectively. The vertical bars indicate $\mathrm{SE}$ with the number of animals in parentheses. ${ }^{*} P<$ 0.05 .

Experiment 6. Age-related changes in plasma calcium and phosphorus after thyroparathyroidectomy. Immature and old rats with mean weights of $50 \mathrm{~g}$ and $360 \mathrm{~g}$, respectively, were thyroparathyroidectomized and bled by orbital sinus puncture before and $1 \frac{1}{2}, 3$, and $6 \mathrm{~h}$ after gland ablation. In both groups of rats thyroparathyroidectomy caused a progressive increase in plasma phosphorus with a greater rise at $3 \mathrm{~h}$ in $50 \mathrm{~g}$ animals $(P<0.01)$ (Fig. $7 b)$. The change in plasma calcium followed a different pattern in the two age groups: in the young animals there was a progressive decrease after thyroparathyroidectomy; however, in the old rats, a significant fall at $6 \mathrm{~h}$ was preceded by a rise in plasma calcium with a peak increase of 0.5 $\mathrm{mg} / 100 \mathrm{ml}$ at $1 \frac{1}{2} \mathrm{~h}$ (Fig. $7 a$ ). At $3 \mathrm{~h}$, the increase in plasma calcium was still significant $(P<0.05)$.

In a preliminary experiment with $500-\mathrm{g}$ rats, the changes in plasma calcium after thyroparathyroidectomy were similar to those observed in $360-\mathrm{g}$ animals

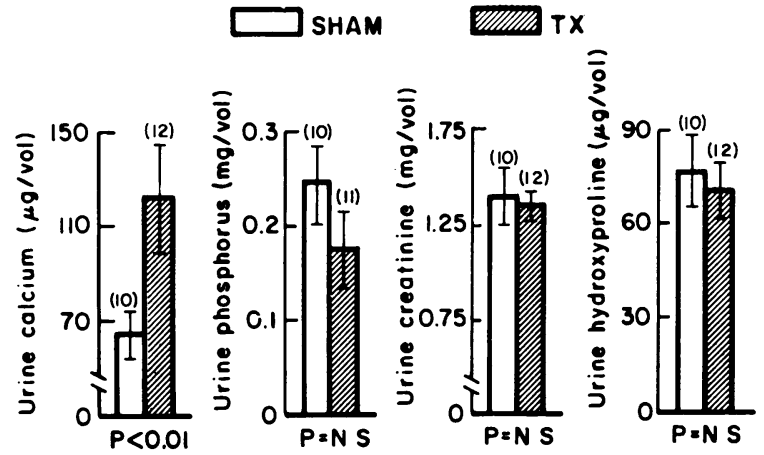

FIgURE 6 Effects of thyroidectomy (TX) on urinary excretion of calcium, phosphorus, creatinine, and hydroxyproline in 380-g rats bearing autoparathyroid transplants. Animals bearing functional parathyroid transplants were thyroidectomized or sham-operated (SHAM) and urine was collected for $3 \mathrm{~h}$ immediately after surgery. The columns indicate means and the vertical bars SE, with the number of animals in parentheses. Same rats as in Fig. 5.
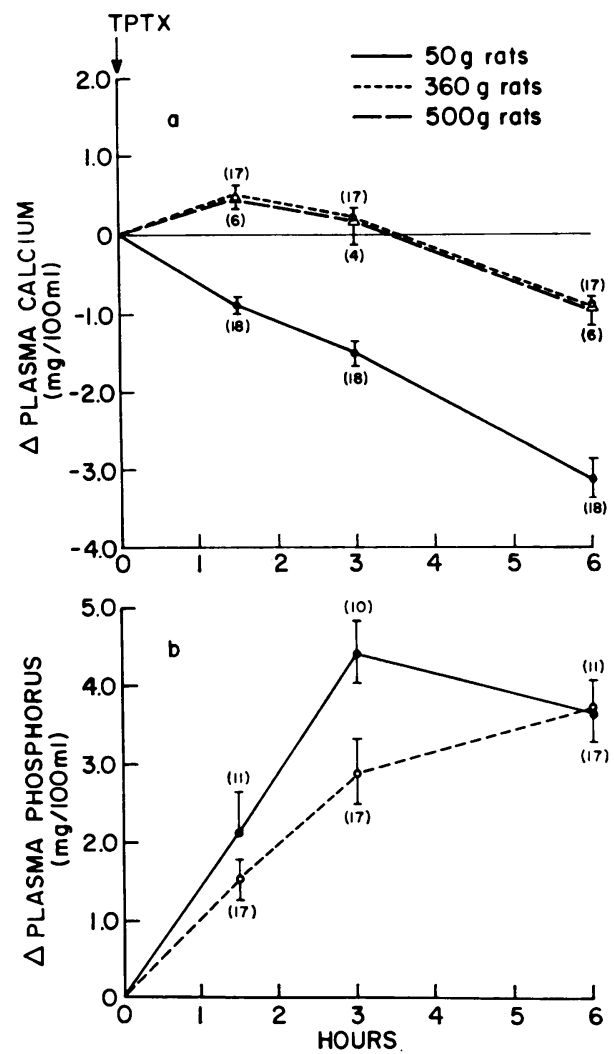

Figure 7 Comparison of changes in plasma calcium and phosphorus after thyroparathyroidectomy (TPTX) in young $(50-\mathrm{g})$ and old (360 and 500-g) rats. Animals were thyroparathyroidectomized and bled by orbital sinus puncture before and $1 \frac{1}{2}, 3$, and $6 \mathrm{~h}$ after surgery. Each point is the mean change in plasma $(a)$ calcium and $(b)$ phosphorus from the pre-TPTX value. The vertical bars indicate SE with the number of animals in parentheses. 
(Fig. 7a). The only difference was that plasma calcium was still increased at $3 \mathrm{~h}(P<0.05)$ only when compared with the corresponding value for shamoperated controls rather than with the prethyroparathyroidectomy plasma calcium level. This is probably because of the small number of animals studied.

\section{DISCUSSION}

The thyroid is the major source of calcitonin in the rat (11). Therefore, surgical thyroparathyroidectomy deprives the animal not only of thyroxine but also of calcitonin and parathyroid hormone. As a result of the relatively long half-life of thyroxine, the thyroid status of the animals is unaltered within the few hours of gland ablation during which our studies were carried out. However, the biological half-lives of calcitonin and parathyroid hormone are considerably shorter. Consequently, interpretation of any acute changes in blood or urinary calcium and phosphorus after thyroparathyroidectomy must consider both hormones. The present investigations were initiated because in 314-g rats plasma calcium remained unchanged $3 \mathrm{~h}$ after thyroparathyroidectomy, while urinary calcium increased markedly (7). The implication of this observation, confirmed in this study, is that calcium transport from bone into blood is enhanced by thyroparathyroidectomy. This view is consistent with the increase in plasma calcium observed after thyroparathyroidectomy in nephrectomized animals. The rise was due specifically to the removal of calcitonin, since thyroidectomy had the same effect on plasma calcium in nephrectomized animals bearing autoparathyroid transplants. Furthermore, an immediate increase in plasma calcium was also observed after thyroparathyroidectomy in unnephrectomized rats weighing 360 and $500 \mathrm{~g}$, and after thyroidectomy in 380-g animals bearing autoparathyroid transplants.

Two points are worth emphasizing. First, in animals weighing $360 \mathrm{~g}$ and over, an immediate increase in plasma calcium after thyroparathyroidectomy precedes the subsequent fall, whereas in immature rats (50 g) the fall is prompt and progressive. Second, although plasma calcium was unchanged $3 \mathrm{~h}$ after thyroparathyroidectomy in animals weighing $318 \mathrm{~g}$, an immediate rise cannot be ruled out, since the animals were not bled at $1 \frac{1}{2} \mathrm{~h}$. Further studies are therefore required to define the precise age at which the transient hypercalcemia is first evident and to determine the relationship of age to its onset, magnitude, and duration. These investigations are currently in progress.

It is of interest that the increase in plasma calcium after thyroidectomy in nephrectomized animals bearing autoparathyroid transplants was directly proportional to the preoperative plasma calcium level. It therefore seems that the immediate rise in plasma calcium after thyroidectomy is greater with increasing parathyroid function, if the preoperative plasma calcium in these rats is a valid index of the functional status of their autoparathyroid transplants. The primary mechanism may, however, be related to the effect of parathyroid hormone on bone turnover rate.

The increase in plasma calcium after thyroparathyroidectomy observed in fasting old rats indicates that in these animals the decrease in the level of circulating calcitonin has a more profound immediate effect on calcium transport from bone into blood than the concommitant decrease in the ambient parathyroid hormone level. Since plasma calcium decreased immediately after thyroparathyroidectomy in $50 \mathrm{-g}$ rats, the importance of the osseous effect of parathyroid hormone relative to calcitonin in the acute regulation of plasma calcium in young animals appears greater.

The immediate transient increase in plasma calcium after thyroidectomy in old animals is in accord with a fine regulatory role for calcitonin (12). Consequently, a defect in calcium homeostasis during prolonged calcitonin deficiency is manifested mainly in the impaired ability of the animal to be effectively protected against hypercalcemic episodes $(1,3,4)$, rather than in sustained hypercalcemia. The observed twofold increase in urinary calcium excretion after thyroidectomy further emphasizes the importance of the basal secretion of calcitonin in conservating calcium and in protecting the animal against hypercalciuria and possibly nephrocalcinosis $(1,13)$. Since thyroidectomy did not alter urinary hydroxyproline excretion, the regulation of plasma calcium by calcitonin appears not to be necessarily associated with changes in bone matrix resorption. The immediate increase in plasma phosphorus in thyroidectomized animals was probably due to increased transport of phosphorus from tissues (bone) into blood. There are two possible explanations of why the hyperphosphatemia was more sustained than the concommitant rise in plasma calcium. First, the urinary excretion of phosphorus did not change significantly; and second, the rate of clearance of phosphorus from the plasma might be decreased by the termination of calcitonin secretion (14).

We conclude from these observations that $(a)$ acute calcitonin deficiency increases plasma calcium in fasting rats. We now know that this rise remained hitherto unappreciated for two reasons: first, it appears to be age-dependent; and second and more important, it is transient. ( $b$ ) In old rats the termination of calcitonin secretion has a greater immediate effect on plasma calcium than the removal of the parathyroids. Since in immature rats the reverse is true, the relative importance of parathyroid hormone and calcitonin in the acute regulation of plasma calcium appears to be age-related. 


\section{ACKNOWLEDGMENTS}

We thank Mr. Barry A. Solomon for his technical assistance.

This work was supported in part by grants from the American Heart Association (71-984) and the National Institutes of Health (AM-15462).

\section{REFERENCES}

1. Munson, P. L., W. H. Schwesinger, C. W. Cooper, T. K. Gray, and T. C. Peng. 1972. Physiological function of thyrocalcitonin. In Endocrinology 1971: Proceedings of the Third International Symposium in Endocrinology. S. Taylor, editor. William Heineman (Medical Books) Ltd., London. 98-107.

2. Milhaud, G., A.-M. Perault, and M. S. Moukhtar. 1965. Etude du méchanisme de l'action hypocalcémiante de la thyrocalcitonine. C. R. Hebd. Seances Acad. Sci. $261: 813-816$.

3. Woodhouse, N. J. Y., and N. D. Barnes. 1968. The response of athyroidal patients to calcium infusion: evidence for an action of thyrocalcitonin. In Calcitonin: Proceedings of the Symposium on Thyrocalcitonin and the C Cells. S. Taylor, editor. William Heinemann (Medical Books) Ltd., London. 361-363.

4. Milhaud, G., A.-M. Perault-Staub, and J.-F. Staub. 1972. Diurnal variation of plasma calcium and calcitonin function in the rat. J. Physiol. (Lond.). 222: 559567.

5. Swaminathan, R., R. F. L. Bates, and A. D. Care. 1972. Fresh evidence for a physiological role of calcitonin in calcium homeostasis. J. Endocrinol. 54: 525-526.
6. Cooper, C. W., P. F. Hirsch, and P. L. Munson. 1970. Importance of endogenous thyrocalcitonin for protection against hypercalcemia in the rat. Endocrinology. 86: 406-415.

7. Kalu, D. N., A. Hadji-Georgopoulos, M. G. Sarr, B. A. Solomon, and G. V. Foster. 1974. The role of parathyroid hormone in the maintenance of plasma calcium level in rats. Endocrinology. 95: 1156-1165.

8. Taussky, H. H., and E. Shorr. 1953. A microcolorimetric method for the determination of inorganic phosphorus. J. Biol. Chem. 202: 675-685.

9. Bonsnes, R. W., and H. H. Taussky. 1945. On the colorimetric determination of creatinine by the Jaffe reaction. J. Biol. Chem. 158: 581-591.

10. Kivirikko, K. I., O. Laitinen, and D. J. Prockop. 1967. Modifications of a specific assay for hydroxyproline in urine. Anal. Biochem. 19: 249-255.

11. Kumar, M. A., and W. C. Sturtridge. 1973. The physiological role of calcitonin assessed through chronic calcitonin deficiency in rats. J. Physiol. (Lond.). 233: 3343.

12. Copp, D. H. 1968. Parathyroid hormone, calcitonin and calcium homeostasis. In Parathyroid Hormone and Thyrocalcitonin (Calcitonin), Proceedings of the Third Parathyroid Conference. R. V. Talmage and L. F. Belanger, editors. Excerpta Medica, Amsterdam. 25-39.

13. Rasmussen, H., and A. Tenenhouse. 1967. Thyrocalcitonin, osteoporcsis and osteolysis. Am. J. Med. 43: 711726.

14. Talmage, R. V., and J. J. B. Anderson. 1972. The effect of calcitonin on ${ }^{32} \mathrm{P}$ disappearance from plasma in parathyroidectomized and nephrectomized rats. Proc. Soc. Exp. Biol. Med. 141: 982-985. 